\title{
Inventario turístico como base para la evaluación de los recursos turísticos del distrito de Chirinos, provincia de San Ignacio, Cajamarca - 2017
}

\section{Tourist inventory as a basis for the evaluation of the turistic resources of the Chirinos, district, San Ignacio province, Cajamarca, 2017}

\author{
Zoila K Vilela C ${ }^{1}$, Lenin Quiñones $\mathrm{H}^{2}$, Ricardo R Alva C ${ }^{3}$, Ulises Gamonal $\mathrm{G}^{4}$.
}

\begin{abstract}
RESUMEN
Desde la última década hasta la actualidad, el turismo es una de las actividades que ha generado un mayor desarrollo socio económico a nivel mundial. El objetivo del presente trabajo de investigación fue elaborar el inventario turístico como base para la evaluación los recursos turísticos en el Distrito de Chirinos, provincia de San Ignacio - Cajamarca - 2017. La población fue los recursos turísticos del Distrito de Chirinos y el muestreo desarrollado fue por conveniencia a objeto de garantizar los objetivos del trabajo propuesto. Se utilizaron los métodos descriptivos, deductivo-inductivo; a través de las técnicas de observación, la fotointerpretación y la recolección directa e indirecta, basándonos en el manual de inventarios propuesto por el Mincetur. El Distrito de Chirinos cuenta con veinticinco (25) recursos turísticos, distribuidos en cinco categorías: Sitios naturales diez (10), manifestaciones culturales dos (2), folclor nueve (9), realizaciones técnicas, científicas, artísticas y contemporáneas dos (2) y acontecimientos programados dos (2). Según la funcionalidad de los recursos turísticos: recursos que no están en operación, con un nivel de jerarquía 1, 2. Según el análisis FODA que se ha realizado, se concluye que los recursos turísticos serían un gran potencial turístico que puestos en valor contribuirían al desarrollo del distrito.
\end{abstract}

Palabras clave: Evaluación, recursos turísticos, inventario turístico, catalogación, jerarquización

\begin{abstract}
From the last decade to the present, tourism is one of the activities that has generated the greatest socio-economic development worldwide. The objective of the present research work was to elaborate the tourist inventory as a base for the evaluation of the tourist resources in the District of Chirinos, province of San Ignacio - Cajamarca - 2017. The population was the tourist resources of the District of Chirinos and the sampling developed was for convenience in order to guarantee the objectives of the proposed work. The descriptive, deductive-inductive methods were used; through observation techniques, photointerpretation and direct and indirect collection, based on the inventory manual proposed by the Mincetur. The Chirinos District has twenty-five (25) tourist resources, distributed in five categories: Natural sites ten (10), cultural manifestations two (2), folklore nine (9), technical, scientific, artistic and contemporary realizations two (2) and scheduled events two (2). According to the functionality of the tourist resources: resources that are not in operation, with a hierarchy level 1, 2. According to the SWOT analysis that has been carried out, it is concluded that tourism resources would be a great tourist potential that value added would contribute to development from District.
\end{abstract}

Keywords: Evaluation, tourist resources, tourist inventory, cataloging, ranking

\footnotetext{
${ }^{1}$ Universidad Nacional Toribio Rodríguez de Mendoza - Chachapoyas. Email: katina.vilela@gmail.com.pe

${ }^{2}$ Universidad Nacional Nacional de Jaén. Email: lenin.quinones@unj.edu.pe

${ }^{3}$ Universidad Nacional Toribio Rodríguez de Mendoza - Chachapoyas. Email: ricardo.alva@untrm.edu.pe

${ }^{4}$ Museo Hermógenes Mejía Solf. Email: gamonaljaen@ hotmail.com
} 


\section{INTRODUCCIÓN}

Desde la última década hasta la actualidad, el turismo es una de las actividades que ha generado un mayor desarrollo socio económico a nivel mundial, porque no solo ha dinamizado de inmediato a numerosos agentes, generando fuentes de trabajo y permitiendo el desarrollo local, regional y nacional; sino también porque representa más de un tercio del valor total del comercio mundial de servicios, (OMT, 2015). En consecuencia, el Perú no ha estado aislado de involucrarse en esta mentalidad. Generándose un desarrollo rápido y espontaneo, por la gran diversidad de sus recursos turísticos y a gran demanda exigente de conocer nuevos lugares.

Cajamarca es una región con gran potencial turístico por lo cual recibe gran afluencia de turistas, principalmente en las provincias de Cajamarca, Cajabamba, Cutervo, Chota y Celendín. Los puntos tradicionales de visita en la región, son los Baños del Inca considerada por la Organización Internacional para el Turismo (OIT) como el balneario termal más hermoso y concurrido en América del Sur, y El cuarto del Rescate. Asimismo, los templos, Las Ventanillas de Otuzco; entre otros lugares más, (Cortázar, 1985). La Provincia Ecológica de San Ignacio, ubicada aproximadamente a 1350 m.s.n.m, está localizada en el extremo norte del departamento de Cajamarca, que corresponde a sí mismo al extremo septentrional de Perú, en la frontera con el Ecuador. Tiene una extensión de 4 990,30 kilómetros cuadrados y se encuentra dividida en 7 distritos. San Ignacio, Chirinos, Huarango, La Coipa, Namballe, San José de Lourdes, Tabaconas. Su población es de 131,239 habitantes, (INEI 2007). Tiene por actividad económica la agricultura la cual se basa exclusivamente al cultivo del café; dejando de lado al turismo del cual se podría sacar mucho provecho porque contamos con la presencia de muchos lugares turísticos; entre ellos destacan en su geografía los andes septentrionales o páramos, cuenta con el Santuario Nacional Tabaconas-Namballe. Asimismo, se puede recrear en pesca (en el río Chinchipe) o dar un paseo en las Balzas o peque peque en el Puerto Ciruelo - Huarango Distrito de Huarango Capital. Varias Cataratas en esta provincia sonllamativas al turismo, además de visitar los petroglifos de Faical u observar el panorama desde el Cerro Campana, (Espinoza Peña, 2014).

El distrito de Chirinos está ubicado en zona de ceja de selva a una altitud de $1858 \mathrm{msnm}$; su clima es frío en sus alturas y caluroso en las partes bajas. Fue fundado en el año de 1548 por el capitán Diego Palomino. Anteriormente Chirinos estuvo ubicado a 30 leguas (165 Km.) de distancia en la parte opuesta y a la orilla de río Chinchipe; se sabe que fue una población considerable, y que tuvo varios anexos que aún se ven sus vestigios en situaciones agradables; pero se ignora las causas de haber perdido éstas ventajas, trasladándose a un terreno tan incómodo como los que en la actualidad ocupa; pero a pesar de esto supo adecuarse y es un Pueblo productor de Café y Arroz por excelencia y ganado por afición; conocido por su gente amistosa y unida frente a las adversidades, protegidos por los 
Inventario turístico como base para la evaluación de los recursos turísticos del distrito de Chirinos

bosques naturales del Gran Chinchiquilla, con sus valles y quebradas que son la grandeza del desarrollo de nuestra región, (Espinoza Soriano, 2016). Su actividad económica principal es la agricultura la cual se basa exclusivamente al cultivo del café.

El distrito de Chirinos, provincia de San Ignacio, departamento de Cajamarca, está ubicado en zona de ceja de selva a una altitud de 1858 m.s.n.m. Su clima es frío en sus alturas y caluroso en las partes bajas. Los límites son: Por el norte con el Distrito de San Ignacio, por el sur con el Distrito de la Coipa y la Provincia de Jaén, con el este con el Distrito de Huarango y por el Oeste con el Distrito de la Coipa. Como se puede observar en la Figura 1, el distrito de Chirinos está conformado por caseríos, anexos y centros poblados.

La historia del actual distrito de chirinos se basa en testimonios que se transmiten de generación en generación quienes afirman que esta zona fue habitada por indígenas probablemente los wampukus de la tradición oral de los aguarunas.

Fue fundado como ciudad española en el año de 1548 por el capitán Diego Palomino. En el valle del rio Chirinos afluente del margen izquierdo del rio Chinchipe; Chirinos estuvo ubicado a 30 leguas (165 Km.) de distancia en la parte opuesta y a la orilla del río Chinchipe.

Los indígenas chirinos, se sabe que fue una población considerable, que según relación de Diego Palomino y la relación de tierras de Jaén eran numerosos y según el censo del año 1561 arrojaba una población de 4,000 habitantes y en el año de 1606 baja a 1,055 habitantes; además tuvieron varios anexos que aún se ven sus vestigios en situaciones agradables; pero se ignora las causas de haber perdido éstas ventajas, trasladándose a un terreno tan incómodo como los que en la actualidad ocupa. Los probables motivos para la reubicación de los Chirinos que al parecer sería una etnia, algunos historiadores dicen que fue por luchas permanente con los Aguarunas y Jíbaros quienes eran tribus guerreras e incendiaban sus viviendas. Se dice que los antiguos pobladores de Chirinos al ser vencidos por las mencionadas etnias llegaron a un lugar denominaba Pukara o Pucará, el mismo que está ubicado en la parte alta del actual pueblo, lo que hoy en día ocupan los Centros Educativos $\mathrm{N}^{\circ} 16485$ y José María Arguedas; fusionándose los nombres llamándose a partir de esa fecha desconocida: San Juan de Chirinos del Pucará.

También se desconoce el motivo de reubicación posterior a lo que hoy ocupamos, pero cuenta la leyenda que en fecha no determinada una niña salió a pastar sus ovejas a la Pampa del Zorzal, en cuyo lugar encontró a otra niña con quien jugaba y la peinaba, esto era de todos los días, los padres de la menor se preocuparon y fueron al lugar, o sea a las Pampas del Zarzal y se dieron con la sorpresa que no era una niña, era la Virgen del Rosario; de esto los padres de la niña comunicaron al pueblo y la llevaron en andas al lugar antes indicado, pero la Virgen no se acostumbraba y siempre se escapaba al lugar donde la habían encontrado. Por todos motivos la población se vio obligada a emigrar a esta zona, construyendo la Iglesia en el lugar donde habían encontrado a la Virgen y al mismo tiempo 
construyeron sus viviendas (Gamonal, 2008).

En la época de la colonia y parte de la república sus límites fuero: Por el norte con el Curato de Zumba de dicha provincia, al oriente con las montañas de Loyola; al occidente con San Felipe y las montañas de Colazay del distrito de este gobierno. Chirinos perteneció a la gobernación de Jaén.

El 3 de marzo de 1729 lograron la titulación de estos terrenos por el margen derecho del rio Chinchipe consiguiendo así la demarcación de su comunidad, después de que el cacique indígena Francisco Mishanango, acompañado por el alcalde don Gaspar Acharico y el regidor don Lorenzo Felipe en nombre de la comunidad presentaran un reclamo por escrito sobre los abusos de los españoles a don Juan Antonio de Ojeda Escamilla, gobernador de justicia mayor y teniente capitán general de la ciudad de Jaén de Brakamoros.

Chirinos es el distrito más antiguo del Perú, su creación como tal data de un 12 de febrero de 1821, que por libre determinación de los pueblos se anexó al Perú y desde aquella fecha perteneció al departamento de Trujillo y desde 1828 a la provincia de Jaén del mismo departamento; en 1855, al ser incorporada la provincia de Jaén al departamento de Cajamarca, Chirinos siguió la misma suerte. Perteneciendo en ese entonces a Jaén desde 1828 hasta el 12 de mayo de 1965, fecha en la que fue incorporado a la provincia de San Ignacio.

Cabe mencionar que este pueblo participó activamente en la Proclamación de la Independencia de la provincia de Jaén un 4 de junio de 1821. Así mismo vale recordar que el distrito de Chirinos fue muy amplio, teniendo bajo su jurisdicción a los que ahora son distritos como: Huarango, San José de Lourdes, San Ignacio, Namballe y la Coipa.

Actualmente en el seno del distrito se encuentran dos comunidades campesinas: San Juan de Chirinos del Pucará y la comunidad de San Pedro de Perico.

Chirinos se le reconoce como pueblo el 03 de mayo de 1955 por Ley No 12301; y 12 de mayo de 1965 por Ley No 15560 pasa a formar parte de la provincia de San Ignacio y por ende al recorte de su jurisdicción, limitándose a lo que es hoy actualmente: Por el norte con los distritos de San Ignacio y San José de Lourdes, de los que está separado por la quebrada de los Cuyes y el río Chinchipe; por el este con el distrito de Huarango; por el sur con los distritos de Bellavista y La Coipa, de los que los separa el río Tabaconas y una quebrada; por el sur oeste con el distrito de La Coipa, (Delgado Carhuajulca, 2002).

El distrito de Chirinos se encuentra formada por dos (2) comunidades, tales como la comunidad san juan de Chirinos y san Pedro de perico.

La primera se caracteriza por ser una zona agrícola que predomina el cultivo de café, dispone de condiciones favorables debido a los diversos pisos ecológicos con climas propicios para su cultivo, se cuenta con café de tipo arábico tales como: caturra, catimor, bourbon, paches y otros, (Delgado 
Carhuajulca, 2002).

Este producto es acopiado y comercializado por la cooperativa las diferentes asociaciones conformados por pequeños productores, los cuales en su mayoría están certificados con reconocidos sellos como orgánico y comercio justo, lo cual les otorga una ventaja competitiva para ingresar a diferentes mercados internacionales. Dentro de ello encontramos a las más importantes la cooperativa agraria cafetalera la prosperidad de chirinos y Cenfro café. Además, también se dedican al cultivo de plátano, yuca, vituca, menestras, granadilla, babaco, etc, (Sena Guerrero, 2014).

La segunda comunidad es una zona cálida donde principalmente se desarrolla la producción de arroz, pues esta zona está compuesta por valles y quebradas lo cual lo hace convierte en tierras fértiles, aptas y fáciles para la producción con riego. También producen mango, ciruela, piña, papaya, y diversas plantas frutales (Delgado Carhuajulca, 2002).

Hoy en día se está fomentando a darles un valor agregado a los productos los cuales están siendo procesados artesanalmente, y obteniendo de ellos: café tostado y molido; harinas, néctares, jaleas, etc.

La presente investigación tubo como finalidad, demostrar el enorme potencial de recursos turísticos que posee el Distrito de Chirinos, debido a que presenta una variada riqueza natural y cultural. Siendo este trabajo un gran insumo para la implementación de corredores turísticos, políticas municipales concernientes a la preservación y conservación de los recursos turísticos, mejoramiento de la calidad de vida de los pobladores, etc.

\section{MATERIALES Y MÉTODOS}

\section{Población}

Recursos turísticos del Distrito de Chirinos, según la Dircetur solo existen dos (02) registrados en el inventario respectivo.

\section{Muestra y muestreo}

La muestra fue de veinticinco (25) recursos turísticos.

El muestreo desarrollado fue intencional o también llamado por conveniencia a objeto de garantizar los objetivos del trabajo propuesto. El criterio de selección de la muestra fue dado por el autor, asesor, bibliografía clasificada proporcionada por el fundador-director del Museo "Hermógenes Mejía Solf" de la Provincia de Jaén y pobladores naturales del Distrito de Chirinos.

\section{Métodos y técnicas}

Se utilizó el método descriptivo: se logró conocer e identificar los recursos y actividades que puedan ser aprovechados para el turismo en el distrito de chirinos, provincia de san Ignacio. Método Deductivo-Inductivo: El método deductivo nos permitió llegar a conclusiones generales, lo cual se 
ha realizo mediante la recopilación de información, el método inductivo además de hechos observables, realizamos entrevistas a personajes importantes del lugar para conocer su opinión respecto a la investigación planteada.

Las técnicas utilizadas para desarrollar esta investigación fueron la observación, y la recolección directa, mediante la aplicación de entrevistas a las autoridades, e indirecta (información recabada de instituciones públicas y privadas).

Otra técnica de evaluación de recursos es la jerarquización de atractivos turísticos.

En la recolección de datos se utilizó las fichas de recopilación de datos para información del inventario de recursos turísticos propuestas en el manual para la formulación del inventario de recursos turísticos a nivel nacional; por el ministerio de comercio exterior y turismo del Perú.

El procesamiento de datos análisis y redacción del informe se realizó en una segunda etapa de gabinete haciendo uso de métodos del analítico deductivo e inductivo.

\section{RESULTADOS}

En el distrito de Chirinos se llegaron a evaluar veintiséis (25) recursos turísticos de los cuales diez (10) corresponden a la categoría de sitios naturales, dos (02) a la categoría manifestaciones culturales, diez (9) a la categoría folclor, dos (02) a la categoría realizaciones técnicas científicas artísticas y contemporáneas y dos (02) a la categoría de acontecimientos programados. En la tabla 1, se puede observar la distribución del inventario de los veintiséis recursos turísticos con sus respectivos porcentajes, de acuerdo a su categoría respectiva.

Tabla 1. Distribución por categorías de los recursos turísticos del distrito de Chirinos

\begin{tabular}{lcc}
\multicolumn{1}{c}{ Categorías } & Cantidad & Porcentaje \\
\hline Sitios naturales & 10 & $39 \%$ \\
Manifestaciones culturales & 2 & $14 \%$ \\
Folclor & 9 & $33 \%$ \\
Realizaciones técnicas C.A.C & 2 & $7 \%$ \\
Acontecimientos programados & 2 & $7 \%$ \\
\hline
\end{tabular}

\section{Sitios naturales}

Este agrupa la mayoría de los recursos turísticos y es considerado como potencial turístico más importante. En esta categoría se pueden encontrar diversos tipos, de los cuales dos (02) son caída de agua, tres (03) son cuerpos de agua, tres (02) montañas, un (01) valle, un (01) rio y una (01) cueva. En la Tabla 2, se puede observar la distribución de la categoría de los sitios naturales, de acuerdo al tipo y subtipo correspondiente, además de localización. 
Inventario turístico como base para la evaluación de los recursos turísticos del distrito de Chirinos

Tabla 2. Recursos turísticos del Distrito de Chirinos en la categoría de sitios naturales.

\begin{tabular}{lccc}
\hline \multicolumn{1}{c}{ Nombre del Recurso } & Localización & Tipo & Sub tipo \\
\hline Catarata Velo de Novia & Caserío Santa lucia & Caídas de agua & Cataratas o cascada \\
Catarata el Perol & Caserío Santa lucia & Caídas de agua & Cataratas o cascada \\
Laguna Brava & Caserío Higuerón & Cuerpo de agua & Laguna \\
Laguna Redonda o Mansa & Caserío Higuerón & Cuerpo de agua & Laguna \\
El Tempano & Caserío Higuerón & Cuerpo de agua & Laguna \\
Cerro portachuelo & Caserío la Florida & Montaña & Cerro \\
Cerro Huayurco & Caserío Higuerón & Montañas & Cerros \\
les De Hawái Y Cunia & Caserío Hawái, Cunia & Valles & --- \\
Perico & C.P. Perico & Rio & --- \\
Katache & Caserío Chulalapa & Cueva & --- \\
\hline
\end{tabular}

\section{Manifestaciones culturales}

Esta categoría considera las diferentes expresiones culturales del distrito, desde las épocas ancestrales. En esta categoría se pueden encontrar diversos tipos, de los cuales dos (02) son pueblo. En la Tabla 3, se puede observar la distribución de la categoría de manifestaciones culturales, de acuerdo al tipo y subtipo correspondiente, además de su localización.

Tabla 3. Recursos turísticos del Distrito de Chirinos en la categoría de manifestaciones culturales.

\begin{tabular}{lccc}
\hline \multicolumn{1}{c}{ Nombre Del Recurso } & Localización & Tipo & Sub tipo \\
\hline Distrito Chirinos & Distrito de Chirinos & Pueblo & Pueblo histórico \\
El Higuerón & Caserío Higuerón & Pueblo & Pueblo tradicionales \\
\hline
\end{tabular}

\section{Categoría de folclor.}

Esta categoría en el distrito de Chirinos compuesta por una (1) danza la cual expresa parte de la historia del distrito, también por cuatro (4) creencias populares siendo las más conocidas, además de su gastronomía. En la tabla 4, se puede observar la distribución de la categoría de folclor, de acuerdo al tipo y subtipo correspondiente, además de su localización. 
Tabla 4: Recursos turísticos del Distrito de Chirinos en la categoría de Folclor.

\begin{tabular}{llll}
\hline Nombre del Recurso & localización & Tipo & Sub tipo \\
\hline Danza de Chirinos & Distrito Chirinos & Danza & \\
$\begin{array}{l}\text { Leyenda del Agua de la } \\
\text { Virgen }\end{array}$ & Distrito Chirinos & $\begin{array}{l}\text { Creencias } \\
\text { populares }\end{array}$ & Leyenda \\
$\begin{array}{l}\text { Leyenda Cerro De Las } \\
\text { Ovejas }\end{array}$ & Distrito Chirinos & $\begin{array}{l}\text { Creencias } \\
\text { populares }\end{array}$ & Leyenda \\
$\begin{array}{l}\text { Leyenda De La } \\
\text { Creación del Caserío } \\
\text { Chulalapa }\end{array}$ & Caserío Chulalapa & $\begin{array}{l}\text { Creencias } \\
\text { populares }\end{array}$ & Leyenda \\
$\begin{array}{l}\text { Pararaico } \\
\text { Shurumbo }\end{array}$ & Distrito Chirinos & $\begin{array}{l}\text { Creencias } \\
\text { populares }\end{array}$ & Costumbres \\
Majote & Distrito Chirinos & Gastronomía & Platos típicos \\
Chivatos & Distrito Chirinos & Gastronomía & Platos típicos \\
Canelazo & Distrito Chirinos & Gastronomía & Dulces típicos \\
\hline
\end{tabular}

\section{Realizaciones técnicas científicas artísticas y contemporáneas.}

Esta categoría comprende aquellas obras actuales pero que muestran el proceso de cultura, civilización y tecnología, con características relevantes para el interés turístico. En esta categoría se encuentra dos (2) de tipo de Centros científicos y técnicos. En la Tabla 5, se puede observar la distribución de la categoría de realizaciones técnicas científicas artísticas y contemporáneas, de acuerdo al tipo y subtipo correspondiente, además de su localización.

Tabla 5: Recursos turísticos del Distrito de Chirinos en la categoría realizaciones técnicas científicas artística y contemporánea.

\begin{tabular}{|c|c|c|c|c|}
\hline Nombre del Recurso & Localización & Categoría & Tipo & Sub tipo \\
\hline $\begin{array}{l}\text { Área Técnica Forestal } \\
\text { Agropecuaria Municipal. }\end{array}$ & Distrito Chirinos & $\begin{array}{l}\text { Realizaciones técnicas } \\
\text { científicas artísticas y } \\
\text { contemporáneas. }\end{array}$ & $\begin{array}{l}\text { Centros } \\
\text { científicos y } \\
\text { técnicos }\end{array}$ & $\begin{array}{l}\text { Jardines botánicos } \\
\text { y viveros }\end{array}$ \\
\hline $\begin{array}{l}\text { Cooperativa } \\
\text { Cafetalera. } \\
\text { "la prosperidad" }\end{array}$ & Distrito Chirinos & $\begin{array}{l}\text { Realizaciones técnicas } \\
\text { científicas artísticas y } \\
\text { contemporáneas. }\end{array}$ & $\begin{array}{l}\text { Centros } \\
\text { científicos y } \\
\text { técnicos }\end{array}$ & $\begin{array}{l}\text { Jardines botánicos } \\
\text { y viveros }\end{array}$ \\
\hline
\end{tabular}

\section{Acontecimientos programados}

Esta categoría agrupa a todos los eventos organizados, actuales o tradicionales, que atraen a los turistas como espectáculos o actores. En esta categoría se encuentra uno (1) de tipo de fiestas patronales. En la Tabla 6, se puede observar la distribución de la categoría de acontecimientos 
Inventario turístico como base para la evaluación de los recursos turísticos del distrito de Chirinos

programados, de acuerdo al tipo y subtipo correspondiente, además de su localización.

Tabla 6: Recursos turísticos del Distrito de Chirinos en la categoría de acontecimientos programados

\begin{tabular}{llll}
\hline Nombre del Recurso & Caseríos & Tipo & Sub tipo \\
\hline $\begin{array}{c}\text { Fiesta religiosa y comercial en honor } \\
\text { al patrón San Juan Bautista }\end{array}$ & Chirinos & Fiestas & Fiestas patronales \\
$\begin{array}{l}\text { Feria del café, Agropecuaria, } \\
\text { Ganadera y Artesanal. }\end{array}$ & Chirinos & Fiestas & Feria \\
\hline
\end{tabular}

En la Tabla 7, se ha realizado un análisis FODA de los recursos turísticos del distrito de Chirinos.

\section{DISCUSIÓN}

La investigación que tiene como título inventario de recursos culturales, gastronómicos y naturales en Cuautla, Ejutla y Tonaya, para su aprovechamiento turístico sustentable. México. Concluye que el levantamiento de un inventario en los municipios de Cuautla, Ejutla y Tonaya, Jalisco, es fundamental para impulsar su desarrollo, ya que el turismo es una de las vías privilegiadas para impulsar la economía y para incrustar en sus estructuras los componentes que la cultura aporta al desarrollo de las comunidades locales. Pues esta conclusión pudimos contrástala con la investigación realizada en el distrito de Chirinos, ya que el propósito de un inventario es brindar información a las instituciones y personas vinculadas al sector público, privado y al público en general, además se convierte en una herramienta útil para la planificación turística, la elaboración de diversos productos (guías, mapas, hojas de rutas, etc.) y la difusión de los diferentes recursos turísticos del distrito de chirinos.

En la investigación titulada evaluación de atractivos para la identificación de nuevos productos turísticos. Su hipótesis consistió en que es posible diversificar la oferta turística a partir de la identificación y puesta en valor de bienes pertenecientes al patrimonio cultural y natural, contribuyendo de este modo al desarrollo integral de las comunidades locales. Ya que se puede hacer una diversificación en la oferta turística a partir de un inventario es por ello la idea de la elaboración de un inventario en el distrito de Chirinos para que a partir de ello se elaboren más y nuevos proyectos para el turismo.

La evaluación el potencial turístico de un determinado lugar nos permite conoces con cuántos recursos contamos y en qué estado se encuentran, para poder desarrollar estrategias para la competencia en cuanto a las variable socioeconómicos, así como la investigación titulada "Evaluación del potencial turístico en la playa norte del Mogote, Bahía de La Paz, B.C.S. México" El objetivo de esta investigación fue evaluar el potencial turístico de la playa norte de El Mogote a 
través del análisis de variables socioeconómicas como la oferta, demanda y competencia, así como la determinación de la aptitud recreativa de la playa, la cual es obtenida mediante indicadores biofísicos representados por los componentes de infraestructura y servicios, ecológico y limpieza. La importancia de realizar un inventario de un determinado lugar no solo es por la identificación de los recursos turísticos, sino que esto también sirve para identificar y recabar información sobre sus aspectos históricos, geopolíticos, biofísicos; tal como nos indica en las diferentes fases del inventario realizado en la provincia de Concepción de la región Junín. Lo cual muestra que es de gran ayuda empezar realizando un diagnóstico de todos los recursos con los que cuenta el distrito de Chirinos tanto históricos, geográficos, económicos.

En la evaluación de los recursos turísticos de Amazonas realizada en la investigación de ZEE (Zonificación Ecológica Económica), tuvieron como objetivo evaluar los principales atractivos y/o recursos turísticos del Departamento de Amazonas. Esto ha sido un proceso de investigación enmarcado a dar a conocer el potencial turístico disponible y aprovechable que tiene este Departamento. Pues en este caso se realizará la evaluación de recursos turísticos del distrito de Chirinos, ya que de esta manera se puede identificar más lugares que puedan incluirse en el inventario del departamento de Cajamarca.

Con la realización del inventario turístico del distrito de chirinos podemos aportar con información para otros proyecto de gran importancia en cuanto al turismo, tal como nos muestra la investigación titulada Condiciones turísticas que presenta la provincia de San Ignacio-región Cajamarca, para su desarrollo como destino turístico tuvo la finalidad de identificar las condiciones turísticas que presenta la provincia de San Ignacio, para desarrollarse como destino turístico, en el que se analizó y describió la atractividad e importancia de los recursos turísticos, naturales y culturales con los que cuenta esta provincia, además se analizó el estado de conservación de la infraestructura existente, así mismo se demuestra la predisposición de la comunidad por trabajar en el desarrollo de la actividad turística. Pues en esta investigación de la provincia de san Ignacio se dejando de lado varios lugares en especial del Distrito de Chirinos. Es bueno la iniciativa para poder realizar investigaciones de cada distrito de la provincia de san Ignacio y poder realizar proyectos que incluyan a los diferentes recursos turísticos tomando en cuenta cada distrito. 
Tabla 7. Análisis FODA de los recursos turísticos del distrito de Chirinos

\begin{tabular}{|c|c|c|c|}
\hline Fortalezas & Oportunidades & Debilidad & Amenazas \\
\hline $\begin{array}{l}\text { Diversidad de recursos turísticos en las } \\
\text { diferentes categorías. }\end{array}$ & $\begin{array}{l}\text { Posibilidades de competir en un turismo de } \\
\text { calidad, no masivo. }\end{array}$ & $\begin{array}{l}\text { Abundancia de recursos } \\
\text { turísticos } \\
\text { desaprovechados y poco valorados. }\end{array}$ & $\begin{array}{l}\text { Deficiencia en la coordinación y } \\
\text { colaboración de las entidades públicas - } \\
\text { privadas. }\end{array}$ \\
\hline $\begin{array}{l}\text { El potencial turístico se encuentra ubicado } \\
\text { en los diferentes espacios geográficos del } \\
\text { distrito. }\end{array}$ & $\begin{array}{l}\text { Pertenecer a una región con Canon minero y } \\
\text { Foncomun. }\end{array}$ & $\begin{array}{l}\text { Escasa promoción e impulso de los recursos } \\
\text { turísticos. }\end{array}$ & $\begin{array}{l}\text { Baja capacidad del gobierno regional y } \\
\text { local para planificar y ejecutar inversión }\end{array}$ \\
\hline $\begin{array}{l}\text { Diferentes formas de acceso hacia el } \\
\text { distrito. }\end{array}$ & $\begin{array}{l}\text { Demanda de turismo vivencial por la } \\
\text { presencia de áreas técnicas agropecuarias y } \\
\text { fincas demostrativas. }\end{array}$ & $\begin{array}{l}\text { Servicio de transporte público deficiente } \\
\text { dentro del distrito. }\end{array}$ & $\begin{array}{l}\text { en el sector. } \\
\text { Deficiencia en los servicios públicos. }\end{array}$ \\
\hline $\begin{array}{l}\text { Surgimiento de nuevos } \\
\text { emprendimientos hoteleros y de servicio de } \\
\text { alimentación. } \\
\text { Proximidad al aeropuerto de Jaén. }\end{array}$ & $\begin{array}{l}\text { Organización de productores de café en } \\
\text { asociaciones agroexportadoras Cooperativa } \\
\text { Agraria Cafetalera "La Prosperidad De } \\
\text { Chirinos", Finca Churupampa, Área Técnica } \\
\text { Municipal, Cenfro Café. }\end{array}$ & $\begin{array}{l}\text { Deficiente cultura turística, debido a que la } \\
\text { mayoría de la población se dedica a la } \\
\text { agricultura. }\end{array}$ & $\begin{array}{l}\text { Distribución a otras actividades } \\
\text { diferentes del presupuesto del canon para } \\
\text { turismo. }\end{array}$ \\
\hline
\end{tabular}




\section{CONCLUSIONES}

Al realizar el inventario del distrito de Chirinos, se identificó 25 recursos turísticos de las diferentes categorías establecidas en el manual de elaboración de inventarios; de los cuales en sitios naturales tenemos la Catarata Velo de Novia, Catarata el Perol, Laguna Brava, Laguna Redonda o Mansa, El Tempano, Cerró portachuelo, Cerro Huayurco, Valles De Hawái Y Cunia, Rio Perico, cueva del Katache. Manifestaciones culturales: distrito de chirinos, caserío el higuerón. Folclor: Danza de Chirinos, Leyenda del Agua de la Virgen, Leyenda Cerro De Las Ovejas, Leyenda De La Creación del Caserío Chulalapa, Pararaico, Shurumbo, Majote, Chivatos, Canelazo. Realizaciones técnicas Científicas Artísticas y Contemporáneas: Área Técnica Forestal Agropecuaria Municipal, Cooperativa agraria, Cafetalera "la prosperidad". Acontecimientos programados: Fiesta religiosa y comercial en honor al patrón San Juan Bautista, Feria del café, Agropecuaria, Ganadera y Artesanal. Recursos turísticos que se jerarquizaron para identificar su nivel de importancia, se encuentran según la funcionalidad en: recursos que no están en operación de los cuales tenemos el tempano y el valle de hawai y cunia se encuentran con niveles de jerarquía 1; y 8 con niveles de jerarquía 2 tales como la Catarata Velo de Novia, Catarata el Perol, Laguna Brava, Laguna Redonda o Mansa, Cerró portachuelo, Cerro Huayurco, Rio Perico, cueva del Katache.

En cuanto al análisis situacional se identificaron sus fortalezas, oportunidades, debilidades y amenazas para el desarrollar del turismo, lo cual nos permite hacer frente a situaciones estratégicas de una manera muy sencilla y rápida; y de esta manera nos permite conocer la situación real en que se encuentra el distrito de Chirinos.

\section{REFERENCIAS BIBLIOGRÁFICAS}

Cortázar, P. (1985). Documental del Perú Tomo XIII Cajamarca. Lima: DESA.

Delgado Carhuajulca, U. (2002). Conozcamos un poco de Chirinos. Chirinos.

Espinoza Peña, C. (2014). casfro. Obtenido de http://sanignacio-peru.blogspot.pe/

Espinoza Soriano, W. (septiembre de 2016). Historia de chirnos. Jaen: Banco central de la reserva.

Gamonal Guevara, U. Tupay Tupana, y otros relatos del Alto Marañón. (2008). Editorial Filito. Jaén.

OMT. (2015). Recomendaciones sobre estadísticas del turismo. Madrid, España.

Sena Guerrero, V. (2014). Condiciones turísticas que presenta la provincia de San Ignacio-región Cajamarca, para su desarrollo como destino turístico. Trujillo: UNT. Fac. CC. 